University of South Carolina

Scholar Commons

$7-2010$

\title{
Co-varying Patterns of Physical Activity and Sedentary Behaviors and Their Long-Term Maintenance Among Adolescents
}

Jihong Liu

University of South Carolina - Columbia, jliu@mailbox.sc.edu

Jinseok Kim

Natalie Colabianchi

Andrew Ortaglia

Russell R. Pate

University of South Carolina - Columbia, rpate@mailbox.sc.edu

Follow this and additional works at: https://scholarcommons.sc.edu/

sph_physical_activity_public_health_facpub

Part of the Public Health Commons

\section{Publication Info}

Published in Journal of Physical Activity and Health, Volume 7, Issue 4, 2010, pages 465-474.

Liu, J., Kim, J., Colabianchi, N., Ortaglia, A., \& Pate, R. R. (2010). Co-varying patterns of physical activity and sedentary behaviors and their long-term maintenance among adolescents. Journal of Physical Activity and Health, 7(4), 465-474.

(c) Journal of Physical Activity and Health, 2010, Human Kinetics

This Article is brought to you by the Physical Activity and Public Health at Scholar Commons. It has been accepted for inclusion in Faculty Publications by an authorized administrator of Scholar Commons. For more information, please contact digres@mailbox.sc.edu. 


\title{
Co-varying Patterns of Physical Activity and Sedentary Behaviors and Their Long-Term Maintenance Among Adolescents
}

\begin{abstract}
Jihong Liu, Jinseok Kim, Natalie Colabianchi, Andrew Ortaglia, and Russell R. Pate
Background: We examined the covarying patterns of physical activity and sedentary behaviors among adolescents and their long-term maintenance. Methods: Data came from the National Longitudinal Study of Adolescent Health (1995-2002). We used latent class analysis to identify distinct covarying patterns in adolescence. Logistic regression models were used to predict odds of meeting moderate-to-vigorous physical activity (MVPA) recommendations ( $\geq 5$ bouts/week) and exceeding screen time guidelines ( $>2$ hours/day) 6 years later based on their adolescent class profile. Results: Five classes for each gender were identified and labeled as low physical activity (PA)/low sedentary behaviors (SED), moderate (Mod) PA/high (HI) SED, Mod PA/low SED, HI PA/low SED, and HI PA (except skating/biking)/low SED. Compared with low PA/low SED, males and females in Mod PA/low SED, HI PA/low SED, and HI PA (except skating/biking)/low SED classes had increased odds of meeting MVPA recommendations in young adulthood. Mod PA/HI SED had higher odds of exceeding screen time guidelines in young adulthood (adjusted odds ratio [AOR] for females: 1.67, 95\% CI: 1.00-2.81; AOR for males: 3.31, 95\% CI: 1.80-6.09). Conclusions: Findings are useful to aid the development of multifactorial interventions that promote physical activity and reduce screen time among adolescents transitioning to adulthood.
\end{abstract}

Keywords: leisure-time exercise, physical inactivity, latent class analysis

With obesity emerging as a major public health crisis, physical activity and sedentary behaviors (such as $\mathrm{TV}$ or video viewing, video or computer game use) are key targets for altering energy balance in preventing and reducing obesity. To date, physical activity and sedentary behaviors have been studied as independent actions in most cases ${ }^{1,2}$ and rarely as covarying behaviors. ${ }^{3-5}$ When they are considered together, often investigators would specify covarying patterns as concordance and disconcordance of a summary physical activity score and sedentary behaviors (eg, high physical activity/high sedentary, high physical activity/low sedentary). However, physical activity and sedentary behaviors are multidimensional and can form multiple patterns, differing in type, intensity and setting. For example, not all youths who watch excessive amounts of television are inactive, ${ }^{3}$ presumably indicating divergent behaviors can coexist. In addition, not all active youths participate in the same types of activities. Understanding natural rather than investigator-specified covarying patterns of health behaviors and its predictive power for future physical activity and sedentary behaviors

Liu, Colabianchi, and Ortaglia are with the Dept of Epidemiology \& Biostatistics, University of South Carolina, Columbia, SC. Kim is with the College of Social Work, University of South Carolina, Columbia, SC. Pate is with the Dept of Exercise Science, University of South Carolina, Columbia, SC. will significantly aid the development of appropriate multifactorial interventions that promote tailored physical activity and may help to harness the obesity epidemic.

Existing studies on the multidimensional patterning of health behaviors have mainly focused on diet and other health behaviors. ${ }^{6-8}$ Nelson et al were among the first to study the covarying patterning of physical activity and sedentary behaviors using cluster analysis methods. ${ }^{5,9}$ Cluster analysis is an exploratory analysis tool used to group similar subjects into respective categories based on proximity measures between observations. Using the data from the National Longitudinal Study of Adolescent Health (Add Health), Nelson et al examined 16 physical activity and sedentary behaviorrelated variables, including both physical activity and sedentary behaviors, and related alternate measures (such as numbers of academic clubs, sports teams, and individual sports in the school; frequency of physical activity at school; and the likelihood of making own TV decisions, playing sports with a parent, and using a recreation center). This analysis produced 7 clusters: $\mathrm{C} 1$, high TV/video, video gaming; C2, high skating, video gaming; $\mathrm{C} 3$, high sports participation with parents, high overall sports participations; $\mathrm{C} 4$, use of neighborhood recreational centers, high sports participation; C5, TV viewing limited by parents, moderate participation in school physical education; C6, low parental TV control, reporting few activities overall; and C7, active in school. ${ }^{5}$ 
The large number of clusters found by Nelson et al might result from the statistical method they used. Thus, in this study, we sought to identify the distinct covarying patterns of physical activity and sedentary behaviors using latent class analysis (LCA), a method which uses statistical criteria to determine class membership and model fit. ${ }^{10}$ The details about the differences between these 2 methods are discussed in the section below. We did not include related alternate measures because they are enabling factors for physical activity and sedentary behaviors rather than actual behaviors.

Our study had the following 3 objectives: 1) to identify distinct covarying patterns of physical activity and sedentary behaviors among adolescents and describe the characteristics of adolescents in each class profile, 2) to examine how the covarying patterns in adolescence can predict meeting moderate-to-vigorous physical activity (MVPA) recommendations in young adulthood, and 3) to examine how the covarying patterns in adolescence can predict exceeding screen time guidelines in young adulthood.

\section{Data and Methods}

\section{Data Source}

Data were from the National Longitudinal Study of Adolescent Health (Add Health), the largest longitudinal study of a representative sample of adolescents in grades 7 to 12 (ages 11 to 21) in the United States. The Add Health was designed to examine the causes of health-related behaviors. The Add Health included a core sample and additional subsamples of selected ethnic and other groups (more than 20,000 adolescents) in 1994 to 1995 (Wave I). All eligible adolescents who would have been in school during 1996 were reinterviewed in 1996. The follow-up rate was $88 \%$ (Wave II). In 2001 to 2, 15,197 participants who were eligible in Wave I were reinterviewed (Wave III). The survey design, sampling frame, and interview methods have been described elsewhere ${ }^{11}$ and on the study website (http://www.cpc.unc.edu/addhealth). This study was approved by the Institutional Review Board of the University of South Carolina.

\section{Measures of Physical Activity and Sedentary Behaviors}

In the in-home interviews (Waves I \& II), adolescents were asked to report their daily physical activities and sedentary behaviors using a 7-day recall questionnaire, which was commonly used in other large-scale epidemiologic studies. ${ }^{12,13}$ Daily physical activities were assessed in 5 questions. Each was worded as such, "during the past week, how many times did you ..." and followed by 5 types of activity: 1) housework (eg, cleaning, cooking, laundry, yard work, or caring for a pet); 2) hobbies (eg, collecting baseball cards, playing a musical instrument, reading, or doing arts and crafts); 3) skating/biking (eg, roller-skating, skate-boarding, rollerblading, or bicycling); 4) active sports (eg, baseball, softball, basketball, soccer, swimming, or football); and 5) exercise (eg, jogging, walking, karate, jumping rope, gymnastics or dancing). The following scores were assigned to each category for these questions: 0 (not at all), 1.5 ( 1 or 2 times), 3.5 ( 3 or 4 times), and 5 (5 or more times). The same questions for physical activities were asked in Waves I and II. Wave III added new activities applicable to young adults within different categories listed above (eg, drama, singing, shopping for fun in the hobby group; wrestling, cycle racing, martial arts for exercise group etc.). In addition, Wave III also asked the frequencies of doing new activities applicable to young adults such as weight lifting/strength training.

Activities were translated into metabolic equivalent (MET) values. One MET is defined as the energy expenditure associated with quiet sitting. According to the Compendium, ${ }^{14}$ housework (except cleaning) and hobbies are light activities that cost 1 to 3 METs, while skating/ biking, active sports, and exercise cost 5 to 8 METs. Add Health lumped activities with similar METs into 1 question as shown above, thus in our analysis MVPA included activities with 5 to 8 METs, instead of $\geq 3$ METs used in some publications. ${ }^{15}$

Using available information, we developed a measure of meeting the physical activity recommendations defined as participating in 5 or more bouts of MVPA per week. To better understand the usual behavior patterns for adolescence, we created an average of Waves I and II for the meeting MVPA recommendations measure (over $99.9 \%$ of the sample). To assess the changes in physical activity and sedentary behaviors from adolescence (Waves I and II) to adulthood (Wave III), we also calculated a measure of meeting MVPA recommendations at Wave III. The definition of MVPA in Wave III was the same as Waves I and II except we added weight lifting (6 METs) in Wave III. For 6 respondents who had missing data in Wave I but not Wave II or vice versa, data from 1 time point was used. Similar definition or methods were used in other publications using Add Health data., ${ }^{5,16}$

Sedentary behaviors were assessed in all waves of Add Health via 3 questions. Each was worded as such "How many hours a week do you ..." and followed by activities like watching television and videos, and playing video or computer games. Wave III added additional questions applicable to young adults, for example, using a computer for surfing the Web, exchanging e-mail, or participating in a chat room. Answers to these questions were summed to create the total screen time (hours/week) that adolescents spent on sedentary activities. An average of total hours spent in sedentary activities in Waves I and II was calculated to assess the usual sedentary behavior in adolescence. The total hours in sedentary activities in Wave III was used to assess their level of sedentary behaviors in young adulthood. Four respondents who had impossible values ( $>168$ hours/week) were recoded as 168 hours. Using national guidelines, ${ }^{17,18}$ we defined exceeding recommended total screen time as $>2$ hours of screen time per day. 


\section{Measurements of Covariates}

A number of sociodemographic variables were examined in relation to the covarying patterns of physical activities and sedentary behaviors. They were: 1) adolescents' age, gender, race/ethnicity (non-Hispanic White, nonHispanic Black, Hispanic, Asian/Pacific-Islander, and others), and nativity (US-born vs. foreign-born) from the in-home questionnaire in Wave I; 2) the highest parental education $(<$ high school, high school graduate or some college, college graduate or more) and household income from the Parental survey in Wave I; and 3) in school status at Wave II. In Wave I, all participants in Add Health were in school.

\section{Statistical Analysis}

Developing Covarying Patterns Using Latent Class Analysis (LCA). LCA was used to determine covarying patterns of usual physical activity and sedentary behaviors at adolescence. The mean scores of 5 physical activity variables and 1 sedentary behavior measure at Waves I and II were included into our LCA analysis. LCA is often called a person-oriented approach, as opposed to a variable-oriented approach, because LCA focuses on the relationships among individuals under the assumption that data were drawn from more than 1 population. ${ }^{19-21}$ This technique uses maximum likelihood procedures to separate respondents into an optimal number of unobserved (ie, latent) classes characterized by meaningful and mutually distinctive subgroups. Specifically, this analysis began with a 1-class model (ie, all adolescents share the same pattern of physical activity and sedentary behaviors) and added an extra class until the best fitting model was found. The Lo-Mendell-Rubin likelihood ratio tests $^{22}$ and the Bayesian information criteria (BIC) were used to determine the optimal number of classes and the best fitting model.

Compared with traditional cluster analysis, LCA has 2 statistical advantages. First, LCA uses model-based posterior membership probabilities estimated by maximum likelihood methods to determine class membership for each case and model fit. ${ }^{10}$ Cluster analysis does not use probability-based classification and assigns each case into only 1 cluster, which may not be conceptually reasonable when the clusters overlap. ${ }^{23,24}$ Second, LCA allows for the simultaneous modeling of covariates to determine the final number of classes within the data, which is not available in cluster analysis. ${ }^{23,24}$

The procedure for finding optimal number of classes was conducted on full cohort and gender-specific samples. Gender-specific and full cohort LCA models were estimated and compared against each other. The significant likelihood ratio test (chi-square [30, 1962.97], $P<.001)$ indicated that the optimal model in terms of model fit for the data were gender specific, thus the results from gender-specific models are presented. We also estimated the same LCA model adjusting for covariates to examine the association between LCA class membership and sociodemographic characteristics. If substantial discrepancy between the LCA models with and without covariates is found, the model with covariates should be presented. ${ }^{25}$ In this study, we found virtually no changes in the LCA models with and without covariates, thus we presented the model without covariates for simplicity.

Three analytic samples were used to complete 3 objectives for the study (ie, examination of covarying patterns, longitudinal analysis on meeting MVPA recommendations in young adulthood, and longitudinal analysis related to meeting screen time recommendations in young adulthood). To develop the covarying patterns of physical activity and sedentary behaviors at Waves I and II, we restricted our analysis to 13,339 adolescents ( 6563 boys and 6776 girls) who were interviewed in both Wave I and II after excluding 100 adolescents who had any type of physical disabilities and 129 females who were pregnant at the interview time in either Wave I or II. Details on the other 2 subsamples derived from these 13,339 adolescents are discussed in the section below.

Descriptive Analyses of Covarying Patterns. We assessed the profiles that characterized and contrasted these subgroups by describing the distribution of physical activity and sedentary behavior variables within each class (subgroup). The sociodemographic characteristics of adolescents in each class were described and compared between classes using Wald tests. All the tests were adjusted with Bonferroni corrections for multiple comparisons.

Long-Term Maintenance of Physical Activity and Sedentary Behaviors. The percentages of participants meeting national physical activity recommendations and exceeding screen time guidelines by the class profiles were compared at adolescence (Waves I \& II, 1995-96) and young adulthood (Wave III, 2001-02). Logistic regression models were used to determine the impact of the class profiles at adolescence on the likelihood of meeting national physical activity recommendations and exceeding screen time guidelines during the critical transition from adolescence to adulthood after adjusting for potential confounders including meeting these guidelines at adolescence. For the analysis of meeting MVPA physical activity recommendation in young adulthood, we restricted our sample to 8254 participants (4299 females, 3955 males) who were interviewed in all 3 waves of the Add Health. We excluded 2697 participants who were interviewed in both Wave I and II but not in Wave III. Other exclusions include 30 participants with missing values in outcome variables in Wave III and 2358 with missing values in covariates ( 2353 were due to missing information on household income). The sample size for the analysis of exceeding screen time guideline was slightly different due to missing values in outcome variable (4289 females, 3956 males). Because income is an important characteristic to be used to characterize the socioeconomic background of the participants in different class profiles and is more sensitive than parental education, despite of its large missing values, we have kept this variable in our analyses. 
The longitudinal poststratification sampling weights provided with the Add Health data were used to account for persons who could not be located or refused to participate and for the fact that the school served as the primary sampling unit and US region was a stratification variable. Survey design effects of multiple stage cluster sampling were controlled in all analyses. Mplus $5.1^{26}$ was used to determine covarying patterns and the remaining analyses were conducted using STATA Version 10.

\section{Results}

\section{Covarying Patterns of Physical Activity and Sedentary Behaviors}

After we included the averages from Waves I and II of all 5 types of physical activities (such as housework, hobbies, skating/biking, active sports, and exercise) and total screen time for sedentary activities (such as watching TV, videos, playing videos or computer games) into our model, the LCA identified 5 covarying patterns of physical activity and sedentary behaviors among adolescents. The covarying patterns looked similar for males and females (see Figures 1 and 2) although the absolute frequencies of the behaviors were different. For simplicity we used the same labels to characterize these patterns for both males and females.

- Class 1: Adolescents who had lower frequencies in all 5 physical activities and low screen time, labeled as low PA/low SED

- Class 2: Adolescents who had moderate frequencies in all activities but high screen time, labeled as Mod $\mathrm{PA} / \mathrm{HI}$ SED
- Class 3: Adolescents who had moderate frequencies in all activities and low screen time labeled as Mod PA/low SED

- Class 4: Adolescents who had high frequencies in all activities, low screen time, labeled as HI PA/low SED

- Class 5: Adolescents who had high frequencies in all activities except skating/biking, low screen time, labeled as HI PA (except skating/biking)/low SED.

The terminology of high, moderate, and low was based on the relative frequencies of specific activities and sedentary time across the 5 classes within each gender in our study population. Although the class profiles in each gender were very similar, the mean frequencies of specific activities differed by gender. Across different classes, females reported higher frequencies in household chores than males. Males appear to have a higher frequency of sports participation than females, while females in each class appear to have a higher frequency of exercise than males. Finally mean daily screen time was higher among males than females in each class (Table 1).

The proportion of children classified into each class also varied by gender. For males, the top 3 classes were low PA/low SED (29.9\%), HI PA (except skating/biking)/ low SED (29.2\%), and Mod PA/low SED (28.3\%). For females, more than half of them $(55.7 \%)$ were in low PA/ low SED class, followed by Mod PA/Low SED (18.3\%), and HI PA (except skating/biking)/low SED (18.2\%). Fewer females were in HI PA/low SED (4.9\%) and Mod PA/HI SED $(3.0 \%)$ than males $(8.4 \%, 4.2 \%$ respectively) (Table 1).

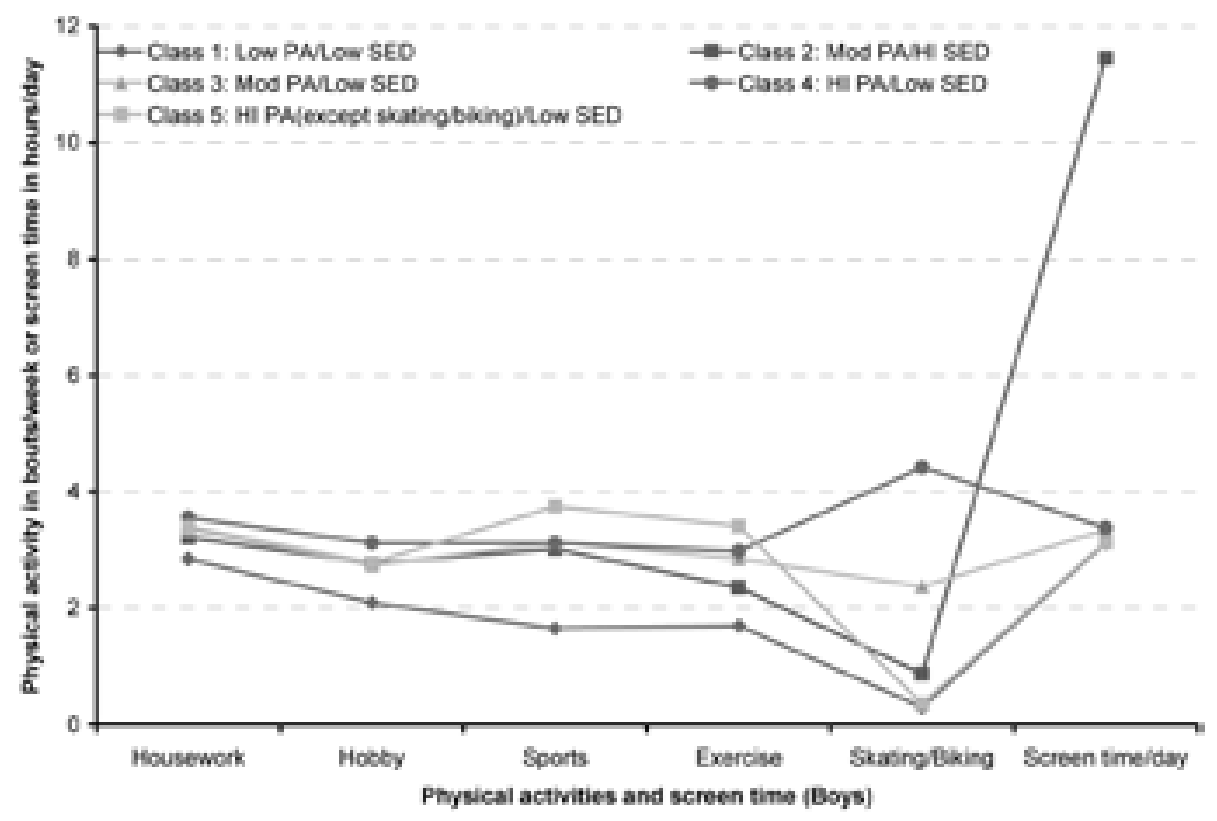

Figure 1 - Covarying patterns of physical activity and sedentary behaviors among adolescents, National Longitudinal Study of Adolescent Health (Boys). 


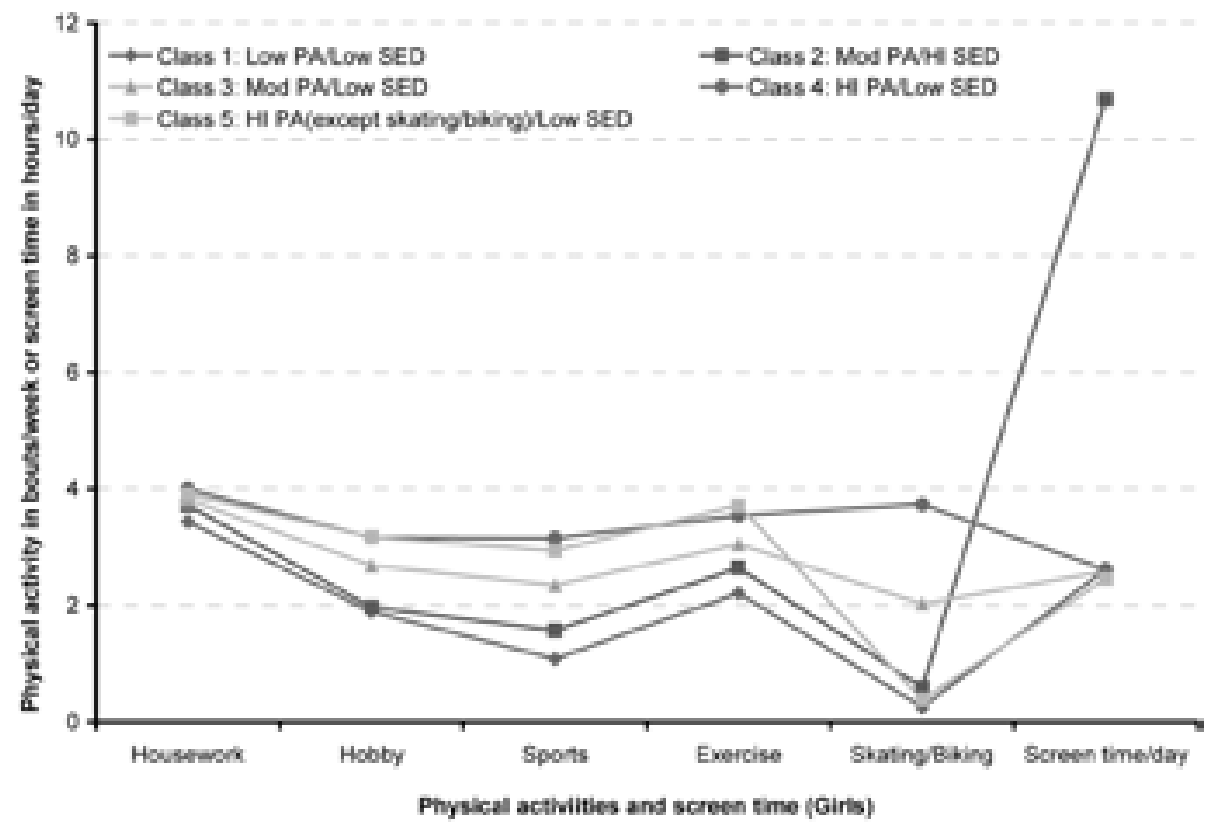

Figure 2 - Covarying patterns of physical activity and sedentary behaviors among adolescents, National Longitudinal Study of Adolescent Health (Girls).

Table 1 Frequency of Specific Activities and Total Sedentary Time by Covarying Classes of Physical Activity and Sedentary Behaviors, National Longitudinal Study of Adolescent Health, Mean (Standard Errors) $(n=13,339)$

\begin{tabular}{|c|c|c|c|c|c|c|}
\hline & $\begin{array}{l}\text { Class 1: Low } \\
\text { PA, low SED }\end{array}$ & $\begin{array}{c}\text { Class 2: Mod } \\
\text { PA, HI SED }\end{array}$ & $\begin{array}{l}\text { Class 3: Mod } \\
\text { PA, Low SED }\end{array}$ & $\begin{array}{c}\text { Class 4: HI } \\
\text { PA, Low SED }\end{array}$ & $\begin{array}{c}\text { Class 5: HI PA } \\
\text { (except skating), } \\
\text { low SED }\end{array}$ & Total \\
\hline \multicolumn{7}{|l|}{ Males } \\
\hline Total $(\mathrm{n}, \%)^{*}$ & 1963 (29.9) & $276(4.2)$ & $1859(28.3)$ & $548(8.4)$ & 1917 (29.2) & 6563 \\
\hline Housework & $2.81(0.04)$ & $3.15^{\mathrm{b}}(0.08)$ & $3.38^{\mathrm{a}, \mathrm{b}}(0.04)$ & $3.59^{\mathrm{a}}(0.08)$ & $3.50^{\mathrm{a}}(0.04)$ & 3.26 \\
\hline Hobby & $2.01(0.05)$ & $2.63^{\mathrm{a}}(0.12)$ & $2.77^{\mathrm{a}}(0.06)$ & $3.31(0.07)$ & $2.82^{\mathrm{a}}(0.06)$ & 2.62 \\
\hline Sports & $1.52(0.04)$ & $2.98^{\mathrm{b}}(0.12)$ & $3.12^{\mathrm{b}}(0.05)$ & $3.17^{\mathrm{b}}(0.12)$ & $3.90(0.04)$ & 2.87 \\
\hline Exercise & $1.58(0.04)$ & $2.25(0.11)$ & $2.83^{\mathrm{b}}(0.05)$ & $3.00^{\mathrm{b}}(0.08)$ & $3.54(0.04)$ & 2.66 \\
\hline Skating & $\mathbf{0 . 2 8}^{\mathrm{a}}(0.01)$ & $0.93(0.07)$ & $2.40(0.02)$ & $4.51(0.03)$ & $\mathbf{0 . 3 2} 2^{\mathrm{a}}(0.01)$ & 1.37 \\
\hline Screen time (hrs/wk) & $\mathbf{2 2 . 0 3}^{\mathrm{b}}(0.58)$ & $81.66(1.65)$ & $\mathbf{2 3 . 2 8}^{\mathrm{b}}(0.60)$ & $\mathbf{2 2 . 7 2}^{\mathrm{b}}(0.98)$ & $22.00^{\mathrm{b}}(0.57)$ & 25.08 \\
\hline \multicolumn{7}{|l|}{ Females } \\
\hline Total $(\mathrm{n}, \%)^{*}$ & 3775 (55.7) & $202(3.0)$ & $1237(18.3)$ & $332(4.9)$ & $1230(18.2)$ & 6776 \\
\hline Housework & $\mathbf{3 . 4 3}^{\mathrm{b}, \mathrm{c}}(0.03)$ & $3.76^{\mathrm{a}, \mathrm{b}}(0.12)$ & $\mathbf{3 . 7 6}^{\mathrm{c}}(0.05)$ & $4.05^{\mathrm{a}}(0.08)$ & $3.97^{\mathrm{a}}(0.05)$ & 3.63 \\
\hline Hobby & $1.86^{\mathrm{b}}(0.03)$ & $\mathbf{1 . 8 8}^{\mathrm{b}}(0.13)$ & $2.67(0.06)$ & $3.23^{\mathrm{a}}(0.10)$ & $3.39^{\mathrm{a}}(0.06)$ & 2.38 \\
\hline Sports & $1.11(0.03)$ & $1.47(0.12)$ & $2.47(0.07)$ & $3.16^{\mathrm{a}}(0.12)$ & $3.28^{\mathrm{a}}(0.06)$ & 1.90 \\
\hline Exercise & $2.19^{\mathrm{a}}(0.04)$ & $\mathbf{2 . 4 6} \mathbf{6}^{\mathrm{a}}(0.12)$ & $3.03(0.05)$ & $3.52(0.08)$ & $3.92(0.04)$ & 2.75 \\
\hline Skating & $\mathbf{0 . 2 4}(0.01)$ & $0.60(0.09)$ & $1.99(0.02)$ & $3.75(0.04)$ & $0.35(0.02)$ & 0.80 \\
\hline Screen time (hrs/wk) & $\mathbf{1 7 . 8 2}^{\mathrm{b}}(0.49)$ & 76.95 (2.08) & $\mathbf{1 7 . 5 0}^{\mathrm{b}}(0.52)$ & $\mathbf{1 9 . 2 0}^{\mathrm{b}}(1.18)$ & $\mathbf{1 7 . 0 1}^{\mathrm{b}}(0.65)$ & 19.28 \\
\hline
\end{tabular}

* Unweighted sample sizes and weighted percentages were presented.

a,b,c In each row, means with the same letter were not significantly different from each other at the 0.05 level. Italicized and boldface numbers were significantly the highest among the classes. Those in boldface only were significantly the lowest. 
These classes varied by sociodemographic characteristics (Table 2). Adolescents in low PA/low SED class were older. Females in low PA/low SED were more likely to be Hispanics than females in Mod PA/low SED and HI PA/low SED classes. Adolescents in Mod PA/HI SED class were more likely to be black (35\% for males, $50 \%$ for females), come from low income families, and almost all of them were born in the US. Adolescents in Mod PA/low SED class were mainly white $(68 \%$ for males, $72 \%$ for females). In the female sample, the Mod PA/low SED class had a lower proportion born in the US (93\%) as compared with the Mod PA/HI SED and HI PA/low SED. Adolescents in HI PA/low SED class were younger (males only) and mainly white (78\% for males, $83 \%$ for females). Adolescents in HI PA (except skating)/low SED class were almost all in school.
Likelihood of Meeting MVPA Recommendations. In adolescence, the proportion of boys who met MVPA recommendations was lowest among low PA/low SED $(21 \%)$ and highest in HI PA/low SED Class (99\%) and HI PA (except skating/biking)/low SED Class (99\%). At young adulthood, the proportion of boys meeting MVPA recommendations decreased in 4 classes except low PA/low SED. The magnitude of reduction was larger among the boys who had the highest proportion of meeting MVPA recommendations in adolescence (Table 3 ). Similar patterns were found among females. Females in HI PA classes (classes 4 and 5) were almost all meeting MVPA recommendations in adolescence. Females in low PA/low SED class had the lowest percentage of meeting MVPA recommendations (26\%) followed by females in Mod PA/HI SED class (45\%). From adolescence to

Table 2 Sociodemographic Characteristics of Covarying Classes, by Gender, Mean (Standard Errors).

\begin{tabular}{|c|c|c|c|c|c|c|}
\hline & $\begin{array}{l}\text { Class 1: Low } \\
\text { PA, low SED }\end{array}$ & $\begin{array}{c}\text { Class 2: Mod } \\
\text { PA, HI SED }\end{array}$ & $\begin{array}{l}\text { Class 3: Mod } \\
\text { PA, low SED }\end{array}$ & $\begin{array}{l}\text { Class 4: HI } \\
\text { PA, low SED }\end{array}$ & $\begin{array}{c}\text { Class 5: HI PA } \\
\text { (except skating), } \\
\text { low SED }\end{array}$ & Total \\
\hline \multicolumn{7}{|l|}{ Males } \\
\hline Age & $16.32(0.11)$ & $15.29^{\mathrm{a}}(0.18)$ & $15.17^{\mathrm{a}}(0.12)$ & $14.67(0.11)$ & $15.84(0.11)$ & 15.64 \\
\hline$\%$ White & $0.63^{\mathrm{a}}(0.04)$ & $\mathbf{0 . 4 5}(0.06)$ & $0.68^{\mathrm{a}}(0.03)$ & $0.78(0.03)$ & $0.62^{\mathrm{a}}(0.03)$ & 0.70 \\
\hline$\%$ Black & $0.14^{\mathrm{a}}(0.02)$ & $0.35(0.06)$ & $0.13^{\mathrm{a}}(0.02)$ & $\mathbf{0 . 0 4}(0.01)$ & $0.17^{\mathrm{a}}(0.03)$ & 0.15 \\
\hline$\%$ Hispanic & $0.15^{\mathrm{a}}(0.02)$ & $0.12^{\mathrm{a}}(0.03)$ & $0.11^{\mathrm{a}}(0.02)$ & $0.09^{\mathrm{a}}(0.02)$ & $0.12^{\mathrm{a}}(0.02)$ & 0.12 \\
\hline$\%$ Asian & $0.04^{\mathrm{a}}(0.01)$ & $0.02^{\mathrm{a}}(0.01)$ & $0.04^{\mathrm{a}}(0.01)$ & $0.04^{\mathrm{a}}(0.01)$ & $0.04^{\mathrm{a}}(0.01)$ & 0.04 \\
\hline $\begin{array}{l}\% \text { parental education } \\
\geq \text { college }\end{array}$ & $0.38^{\mathrm{a}}(0.02)$ & $0.32^{\mathrm{a}}(0.04)$ & $0.35^{\mathrm{a}}(0.02)$ & $0.44^{\mathrm{a}}(0.03)$ & $0.40^{\mathrm{a}}(0.03)$ & 0.38 \\
\hline $\begin{array}{l}\% \text { parental education } \\
<\text { high school }\end{array}$ & $0.12^{\mathrm{a}}(0.02)$ & $0.11^{\mathrm{a}}(0.03)$ & $0.11^{\mathrm{a}}(0.02)$ & $0.07^{\mathrm{a}}(0.02)$ & $0.09^{\mathrm{a}}(0.02)$ & 0.11 \\
\hline $\begin{array}{l}\text { Household income } \\
\text { (in } \$ 1 \mathrm{~K} \text { ) }\end{array}$ & $42.13^{\mathrm{a}}(2.12)$ & 33.01 (2.35) & $45.17^{\mathrm{a}}(2.08)$ & $\mathbf{5 2 . 2 5}^{\mathrm{a}}(3.97)$ & $48.87^{\mathrm{a}}(2.95)$ & 45.56 \\
\hline$\%$ born in US & $\mathbf{0 . 9 2}^{\mathrm{a}}(0.02)$ & $0.99(0.01)$ & $\mathbf{0 . 9 5}^{\mathrm{a}}(0.01)$ & $\mathbf{0 . 9 5}^{\mathrm{a}}(0.01)$ & $0.94^{\mathrm{a}}(0.01)$ & 0.94 \\
\hline$\%$ in school & $\mathbf{0 . 9 7} 7^{\mathrm{b}}(0.01)$ & $0.99^{\mathrm{a}, \mathrm{b}}(0.01)$ & $0.99^{\mathrm{a}}(0.00)$ & $1.00^{\mathrm{a}}(0.00)$ & $0.99^{\mathrm{a}, \mathrm{b}}(0.00)$ & 0.99 \\
\hline \multicolumn{7}{|l|}{ Females } \\
\hline Age & $15.87^{\mathrm{a}}(0.10)$ & $15.42^{\mathrm{a}, \mathrm{b}}(0.25)$ & $14.93^{\mathrm{b}, \mathrm{c}}(0.13)$ & $14.66^{c}(0.15)$ & $15.08^{\mathrm{b}}(0.11)$ & 15.46 \\
\hline$\%$ White & $0.61(0.03)$ & $\mathbf{0 . 4 0}(0.07)$ & $0.72^{\mathrm{a}}(0.03)$ & $0.83(0.03)$ & $0.72^{\mathrm{a}}(0.03)$ & 0.66 \\
\hline$\%$ Black & $0.17(0.02)$ & $0.50(0.07)$ & $\mathbf{0 . 1 1}^{\mathrm{a}}(0.02)$ & $\mathbf{0 . 0 7}^{\mathrm{a}}(0.02)$ & $\mathbf{0 . 1 0}{ }^{\mathrm{a}}(0.02)$ & 0.15 \\
\hline$\%$ Hispanic & $0.14^{\mathrm{a}}(0.02)$ & $\boldsymbol{0 . 0 8 ^ { \mathrm { a } , \mathrm { b } }}(0.03)$ & $\mathbf{0 . 0 9}^{\mathrm{b}}(0.02)$ & $\mathbf{0 . 0 6}^{\mathrm{b}}(0.02)$ & $0.11^{\mathrm{a}, \mathrm{b}}(0.02)$ & 0.12 \\
\hline$\%$ Asian & $0.04^{\mathrm{a}}(0.01)$ & $0.01^{\mathrm{a}}(0.01)$ & $0.05^{\mathrm{a}}(0.01)$ & $0.02^{\mathrm{a}}(0.01)$ & $0.03^{\mathrm{a}}(0.01)$ & 0.04 \\
\hline $\begin{array}{l}\% \text { parental education } \\
\geq \text { college }\end{array}$ & $\mathbf{0 . 3 6}^{\mathrm{b}}(0.02)$ & $\mathbf{0 . 3 3}^{\mathrm{a}, \mathrm{b}}(0.05)$ & $\boldsymbol{0 . 4 0 ^ { \mathrm { a } , \mathrm { b } }}(0.03)$ & $\mathbf{0 . 4 8 ^ { \mathrm { a } } ( 0 . 0 4 )}$ & $0.39^{\mathrm{a}, \mathrm{b}}(0.03)$ & 0.38 \\
\hline $\begin{array}{l}\% \text { parental education } \\
<\text { high school }\end{array}$ & $0.12^{\mathrm{a}}(0.1)$ & $0.18^{\mathrm{a}, \mathrm{b}}(0.04)$ & $0.10^{\mathrm{a}, \mathrm{b}}(0.02)$ & $\mathbf{0 . 0 4}^{\mathfrak{c}}(0.01)$ & $\mathbf{0 . 0 7}^{\mathrm{b}, \mathrm{c}}(0.01)$ & 0.11 \\
\hline $\begin{array}{l}\text { Household income } \\
\text { (in } \$ 1 \mathrm{~K} \text { ) }\end{array}$ & $42.84^{\mathrm{a}}(1.72)$ & $26.59(2.66)$ & $47.25^{\mathrm{a}}(2.41)$ & $54.95^{\mathrm{a}}(4.61)$ & $49.05^{\mathrm{a}}(2.64)$ & 45.18 \\
\hline$\%$ born in US & $\mathbf{0 . 9 2}^{\mathrm{c}}(0.01)$ & $1.00^{\mathrm{a}}(0.00)$ & $\mathbf{0 . 9 3}^{\mathrm{c}}(0.01)$ & $0.98^{\mathrm{a}, \mathrm{b}}(0.01)$ & $0.95^{\mathrm{a}, \mathrm{b}, \mathrm{c}}(0.01)$ & 0.93 \\
\hline$\%$ in school & $\mathbf{0 . 9 7} 7^{\mathrm{b}}(0.00)$ & $0.97^{\mathrm{a}, \mathrm{b}}(0.01)$ & $\mathbf{0 . 9 9 ^ { \mathrm { a } , \mathrm { b } }}(0.00)$ & $0.97^{\mathrm{a}, \mathrm{b}}(0.02)$ & $0.99^{\mathrm{a}}(0.00)$ & 0.98 \\
\hline
\end{tabular}

a,b,c In each row, means with the same letter were not different from each other at the 0.05 level. Those italicized and in boldface were the highest for the row, while those in boldface only were the lowest. 
Table 3 Meeting Moderate-to-Vigorous Physical Activity Recommendations in Adolescence (Wave I \& II) and Young Adulthood (Wave III) by Covarying Classes

\begin{tabular}{|c|c|c|c|c|}
\hline \multirow[b]{2}{*}{ Class } & \multirow{2}{*}{$\begin{array}{c}\text { Wave I \& II } \\
\text { Proportion (s.e.) }\end{array}$} & \multirow{2}{*}{$\begin{array}{c}\text { Wave III } \\
\text { Proportion (s.e.) }\end{array}$} & \multicolumn{2}{|c|}{ Wave III } \\
\hline & & & $\begin{array}{l}\text { Model } 1^{*} \text { AOR } \\
(95 \% \mathrm{Cl})\end{array}$ & $\begin{array}{c}\text { Model } 2^{\star \star} \text { AOR } \\
(95 \% \mathrm{Cl})\end{array}$ \\
\hline Males & $\mathrm{n}=5059$ & $\mathrm{n}=5044$ & $\mathrm{n}=3955$ & $\mathrm{n}=3955$ \\
\hline Class 1: low PA, low SED & $0.21(0.02)$ & $0.30(0.02)$ & 1.00 & 1.00 \\
\hline Class 2: Mod PA, HI SED & $0.76(0.05)$ & $0.39(0.05)$ & $1.34(0.86,2.09)$ & $0.97(0.61,1.53)$ \\
\hline Class 3: Mod PA, Low SED & $0.92(0.01)$ & $0.48(0.02)$ & $2.05(1.62,2.60)$ & $1.37(0.99,1.89)$ \\
\hline Class 4: HI PA, Low SED & $0.99(0.01)$ & $0.55(0.03)$ & $2.61(1.87,3.64)$ & $1.66(1.13,2.45)$ \\
\hline Class 5: HI PA (except skating), Low SED & $0.99(0.00)$ & $0.53(0.02)$ & $2.40(1.93,2.99)$ & $1.53(1.11,2.11)$ \\
\hline Females & $\mathrm{n}=5583$ & $\mathrm{n}=5568$ & $\mathrm{n}=4299$ & $\mathrm{n}=4299$ \\
\hline Class 1: low PA, low SED & $0.26(0.01)$ & $0.17(0.01)$ & 1.00 & 1.00 \\
\hline Class 2: Mod PA, HI SED & $0.45(0.06)$ & $0.19(0.04)$ & $1.93(1.08,3.43)$ & $1.79(1.00,3.22)$ \\
\hline Class 3: Mod PA, Low SED & $0.87(0.01)$ & $0.31(0.02)$ & $2.37(1.84,3.05)$ & $1.87(1.41,2.47)$ \\
\hline Class 4: HI PA, Low SED & $0.99(0.01)$ & $0.44(0.05)$ & $3.89(2.59,5.85)$ & $2.93(1.90,4.52)$ \\
\hline Class 5: HI PA (except skating), Low SED & $0.99(0.00)$ & $0.35(0.02)$ & $2.53(1.98,3.24)$ & $1.90(1.41,2.56)$ \\
\hline
\end{tabular}

Abbreviations: AOR, adjusted odds ratio; CI, confidence interval; s.e., standard error.

* Model 1 adjusted for age, race/ethnicity, parent education level, household income, child's nativity (born in U.S or not), in-school status.

** Based on Model 1, Model 2 additionally adjusted for meeting physical activity recommendations in adolescence.

young adulthood, females in all classes experienced large reductions in the percentages of meeting MVPA, range $17 \%$ to $44 \%$.

For males, the odds of meeting MVPA recommendations were not different for those in Mod PA/ HI SED class compared with those in low PA/low SED after adjusting for covariates in adolescence (model 1) while this class was significant for females. However, for both males and females, those in Mod PA/low SED, HI PA/low SED, HI PA (except skating/biking)/low SED all had 2 to 3 times higher odds of meeting MVPA recommendations in young adulthood compared with those in low PA/low SED class. Additional adjustment of meeting MVPA recommendation in adolescence attenuated the relationship but the findings remained significant (Table 3).

Likelihood of Exceeding Screen Time Guidelines. At adolescence (Waves I \& II), the percentage exceeding screen time guidelines reached $100 \%$ for those in Mod PA/HI SED class. In the other classes, the percentages were similar (range for males: $62 \%$ to $65 \%$, for females: $47 \%$ to $54 \%$ ). In young adulthood, these percentages were reduced slightly for Mod PA/HI SED class $(89 \%$ for males, $75 \%$ for females) but did not change much in other classes (Table 4).

For both males and females, Mod PA/HI SED was the only significant predictor of exceeding screen time guidelines in young adulthood. The relationship remained even after adjusting for not meeting screen time guidelines in adolescence (adjusted odds ratios (AOR) for males: 3.31, 95\% confidence interval (CI): 1.80-6.09; AOR for females: 1.67, 95\% CI: 1.00-2.81) (Table 4).

\section{Discussion and Conclusions}

Existing studies examining the multidimensional nature of physical activity and sedentary behaviors in adolescents have used cluster analysis only, ${ }^{4,5,27}$ We used an alternative technique - latent class analysis - to identify unobserved homogenous groups based on physical activity and sedentary behaviors for adolescents. Different from investigator-specified patterns, this approach has provided a rich profile on the types of activities that each class participates in. To our knowledge, this is the first analysis using LCA to examine these behaviors in a large, nationally representative cohort. We believe this is a promising technique that could lead to the development of multicomponent interventions.

We found 5 covarying classes among adolescent males and females, a small number of meaningful classes than what Nelson found. ${ }^{5}$ Findings from this personoriented LCA approach ${ }^{28}$ reaffirm that physical activities and sedentary behaviors should be explored as a holistic profile rather than separate variables..$^{5,29-31}$ For example, our results showed that compared with those groups with a high level of physical activity (HI PA/low SED; HI PA (except skating/biking)/low SED), adolescents who reported the lowest level of overall physical activities (low PA/low SED) were not spending any more hours on screen while they were less likely to meet the MVPA recommendations. Furthermore, those in the Mod PA/ low SED group were more likely to meet physical activity recommendations compared with those in the low PA/low SED group, but those in the Mod PA/HI SED group were not. To our surprise, we only found 1 high sedentary subgroup with moderate physical activity. We 
Table 4 Exceeding Screen Time Guidelines in Adolescence (Wave I \& II) and Young Adulthood (Wave III) by Covarying Classes

\begin{tabular}{|c|c|c|c|c|}
\hline \multirow[b]{2}{*}{ Class } & \multirow{2}{*}{$\begin{array}{c}\text { Wave I \& II } \\
\text { Proportion (s.e) }\end{array}$} & \multirow{2}{*}{$\begin{array}{c}\text { Wave III } \\
\text { Proportion (s.e.) }\end{array}$} & \multicolumn{2}{|c|}{ Wave III } \\
\hline & & & $\begin{array}{c}\text { Model } 1^{*} \text { AOR } \\
(95 \% \mathrm{Cl})\end{array}$ & $\begin{array}{c}\text { Model } 2^{\star \star} A O R \\
(95 \% \mathrm{Cl})\end{array}$ \\
\hline Males & $\mathrm{n}=5059$ & $\mathrm{n}=5044$ & $\mathrm{n}=3956$ & $\mathrm{n}=3956$ \\
\hline Class 1: low PA, low SED & $0.65(0.02)$ & $0.67(0.02)$ & 1.00 & 1.00 \\
\hline Class 2: Mod PA, HI SED & $1.00(0.00)$ & $0.89(0.02)$ & $4.69(2.56,8.59)$ & $3.31(1.80,6.09)$ \\
\hline Class 3: Mod PA, Low SED & $0.64(0.02)$ & $0.66(0.01)$ & $0.93(0.73,1.19)$ & $0.97(0.75,1.24)$ \\
\hline Class 4: HI PA, Low SED & $0.62(0.03)$ & $0.61(0.03)$ & $0.71(0.51,0.97)$ & $0.76(0.54,1.05)$ \\
\hline Class 5: HI PA (except skating), Low SED & $0.64(0.02)$ & $0.64(0.02)$ & $0.92(0.72,1.17)$ & $0.92(0.71,1.19)$ \\
\hline Females & $\mathrm{n}=5583$ & $\mathrm{n}=5556$ & $\mathrm{n}=4289$ & $\mathrm{n}=4289$ \\
\hline Class 1: low PA, low SED & $0.52(0.02)$ & $0.54(0.01)$ & 1.00 & 1.00 \\
\hline Class 2: Mod PA, HI SED & $1.00(0.00)$ & $0.75(0.04)$ & $2.35(1.40,3.96)$ & $1.67(1.00,2.81)$ \\
\hline Class 3: Mod PA, Low SED & $0.48(0.02)$ & $0.49(0.02)$ & $0.88(0.72,1.08)$ & $0.92(0.75,1.12)$ \\
\hline Class 4: HI PA, Low SED & $0.54(0.04)$ & $0.47(0.04)$ & $0.77(0.55,1.08)$ & $0.75(0.54,1.04)$ \\
\hline Class 5: HI PA (except skating), Low SED & $0.47(0.03)$ & $0.50(0.02)$ & $0.93(0.75,1.15)$ & $0.97(0.78,1.21)$ \\
\hline
\end{tabular}

Abbreviations: AOR, adjusted odds ratio; CI, confidence interval; s.e., standard error.

* Model 1 adjusted for age, race/ethnicity, parent education level, household income, child's nativity (born in U.S or not), in-school status.

** Based on Model 1, Model 2 additionally adjusted for exceeding screen time guidelines in adolescence.

did not find other highly sedentary patterns such as low PA/HI SED or HI PA/HI SED which were found in a British study ${ }^{3}$ and would likely be defined as groups in investigator-specified patterns.

Although the same labels were used to describe the classes for males and females, it should be noted that the corresponding classes for males and females may not be identical. The frequencies of behaviors varied between males and females. The most prevalent classes were low PA/low SED (29.9\%) and HI PA (except skating)/low SED $(29.2 \%)$ for males and low PA/low SED for females $(55.7 \%)$. Mod PA/HI SED had the lowest percentages for males $(4.2 \%)$ and females $(3.0 \%)$.

The low PA/low SED group was the most prevalent class especially among females in our data. As compared with other classes, this group was older and had a higher percentage of Hispanics (for females only). Adolescents in this class had the lowest percentages of meeting MVPA recommendations both at adolescence and young adulthood, suggesting that special attention toward this subgroup is needed since low physical activity in adolescence will track until adulthood ${ }^{32}$ and may prevent them from developing active lifestyles later in life.

Although the Mod PA/HI SED class only accounts for $3 \%$ to $4 \%$ of males and females in our sample, they formed a distinctive class. The adolescents in this class spent an excessive amount of time watching TV/video and video gaming. Their sedentary behavior persisted in young adulthood. They were also less likely to meet MVPA recommendations in young adulthood, which was not seen in participants in the Mod PA/Low SED group. Thus, the Mod PA/HI SED subgroup should also be targeted in the interventions focusing on reducing sedentary behaviors and improving physical activity. This class was characterized as having a large proportion of African Americans and low socioeconomic status, which is consistent with prior findings regarding who were most sedentary. ${ }^{12,33}$

Adolescents in highly active classes such as HI PA (except skating/biking)/low SED, HI PA/low SED, or those in moderately active class (Mod PA/low SED) had higher odds of meeting MVPA recommendations in young adulthood as compared with those in low PA/ low SED class. This provides some evidence about the validity of the covarying patterns. However children especially girls in these classes experienced the largest reduction in MVPA while transitioning into adulthood. This result is not a surprising since those who were more active in the past had more room for the reduction over time. Because all these children were enrolled in school, perhaps novel school-based interventions are needed to help them to prevent the physical activity decline during the transition from adolescence to adulthood.

Consistent with prior literature, ${ }^{34}$ we found that screen time tracked better than physical activity from adolescence to adulthood. Overall, it is discouraging that at least $60 \%$ of males and $45 \%$ of females exceeded the screen time guidelines and 1 class (Mod PA/HI SED) reached $100 \%$. A small reduction was observed in the Mod PA/HI SED class in young adulthood but little change was observed in other classes. Because sedentary behaviors are independent risk factors for obesity and chronic diseases, ${ }^{12,35}$ it is important to design more programs to reduce screen time for all adolescents. 
This study is unique in terms of using LCA to identify covarying patterns of physical activity and sedentary behaviors. Compared with Nelson and colleagues, ${ }^{5}$ this study used a LCA and found a smaller number of gender specific covarying patterns of physical activity and sedentary behaviors. However, some limitations of this study warrant consideration: the use of self-reported measures in activity and sedentary behaviors on a limited set of activities and limited data to quantify meeting MVPA recommendations (ie, lack of data on the length of bouts, inability to differentiate moderate and light intensity physical activities with METs score less than 5). Although Add Health was designed to be a representative sample of adolescents at baseline in the US, due to the sample attrition from Wave I to Wave III and additional deletion because of missing values, we noticed that the observations excluded from our longitudinal analysis were more likely to be non-Hispanic black and Hispanic children, came from families with lower household income, and were less likely to meet MVPA recommendations in adolescence. Thus, this might have created a potential selection bias in our analyses of longterm maintenance of health behaviors. It is necessary for future studies to confirm the utility of LCA to identify covarying patterns using different datasets and from different populations. More in-depth analysis of the psychosocial correlates (such as perceived benefits and barriers, attitudes, social support, and self-efficacy) especially as they relate to demographic differences in each class would be very useful for the design of effective interventions.

In brief, the majority of findings were consistent with prevailing literature to date, thereby lending support for the LCA approach. Our findings suggest that different types of interventions may be warranted for adolescents in different classes. The sociodemographic characteristics of each class can provide initial ideas on target populations. Successful interventions and policies to promote active lifestyles, reduce sedentary behaviors, and therefore prevent obesity among adolescents who are transitioning to young adulthood are greatly needed. Future research should determine whether segmenting target populations into homogeneous groups can help to improve the reach, utilization, and effectiveness of health interventions.

\section{Acknowledgments}

This project was sponsored by Maternal and Child Health Research Program, Health Resources and Services Administration (R40MC08958).

\section{References}

1. Gordon-Larsen P, Adair LS, Popkin BM. Ethnic differences in physical activity and inactivity patterns and overweight status. Obes Res. 2002;10(3):141-149.

2. Robinson TN. Reducing children's television viewing to prevent obesity: a randomized controlled trial. JAMA. 1999;282(16):1561-1567.

3. Marshall SJ, Biddle SJ, Sallis JF, McKenzie TL, Conway TL. Clustering of sedentary behaviors and physical activity among youth: a cross-national study. Pediatr Exerc Sci. 2002;14(4):401-417.

4. Monda KL, Popkin BM. Cluster analysis methods help to clarify the activity-BMI relationship of Chinese youth. Obes Res. 2005;13(6):1042-1051.

5. Nelson MC, Gordon-Larsen P, Adair LS, Popkin BM. Adolescent physical activity and sedentary behavior: patterning and long-term maintenance. Am J Prev Med. 2005;28(3):259-266.

6. Burke V, Milligan RA, Beilin LJ, et al. Clustering of health-related behaviors among 18-year-old Australians. Prev Med. 1997;26(5 Pt 1):724-733.

7. Patterson RE, Haines PS, Popkin BM. Health lifestyle patterns of U.S. adults. Prev Med. 1994;23(4):453-460.

8. Berrigan D, Dodd K, Troiano RP, Krebs-Smith SM, Barbash RB. Patterns of health behavior in U.S. adults. Prev Med. 2003;36(5):615-623.

9. Nelson MC, Gordon-Larsen P. Physical activity and sedentary behavior patterns are associated with selected adolescent health risk behaviors. Pediatrics. 2006;117(4):1281-1290.

10. Bacher J. A probabilistic clustering model for variables of mixed type. Qual Quant. 2000;34(3):223-235.

11. Popkin BM, Udry JR. Adolescent obesity increases significantly in second and third generation U.S. immigrants: the National Longitudinal Study of Adolescent Health. $J$ Nutr. 1998;128(4):701-706.

12. Andersen RE, Crespo CJ, Bartlett SJ, Cheskin LJ, Pratt M. Relationship of physical activity and television watching with body weight and level of fatness among children: results from the Third National Health and Nutrition Examination Survey. JAMA. 1998;279(12):938-942.

13. Heath GW, Pratt M, Warren CW, Kann L. Physical activity patterns in American high school students. Results from the 1990 Youth Risk Behavior Survey. Arch Pediatr Adolesc Med. 1994;148(11):1131-1136.

14. Ainsworth BE, Haskell WL, Whitt MC, et al. Compendium of physical activities: an update of activity codes and MET intensities. Med Sci Sports Exerc. 2000;32(9, Suppl):S498-S504.

15. Okely AD, Booth ML, Hardy L, Dobbins T, DenneyWilson E. Changes in physical activity participation from 1985 to 2004 in a statewide survey of Australian adolescents. Arch Pediatr Adolesc Med. 2008;162(2):176-180.

16. Gordon-Larsen P, Nelson MC, Popkin BM. Longitudinal physical activity and sedentary behavior trends: adolescence to adulthood. Am J Prev Med. 2004;27(4):277-283.

17. American Academy of Pediatrics. Children, adolescents, and television. Pediatrics. 2001;107(2):423-426.

18. American Academy of Pediatrics. Media violence. Committee on Public Education. Pediatrics. 2001;108(5):1222-1226.

19. McCutcheon AL. Latent Class Analysis. Beverly Hills, CA: Sage Publications; 1987.

20. Muthen L, Muthen B. Mplus User's Guide, Release 3.5. Los Angeles: Muthen \& Muthen; 2004.

21. Muthen B, Muthen LK. Integrating person-centered and variable-centered analyses: growth mixture modeling with latent trajectory classes. Alcohol Clin Exp Res. 2000;24(6):882-891.

22. Lo Y, Mendell NR, Rubin DB. Testing the number of components in a normal mixture. Biometrika. 2001;88(3):767-778.

23. Magidson J, Vermunt JK. Latent class models for clustering: a comparison with K-means. Canadian Journal of Marketing Research. 2002;20(1):36-43.

24. Morgan BT, Ray APG. Non-uniqueness and inversion in cluster analysis. Appl Stat. 1995;44:117-134. 
25. Muthen B. Latent variable analysis: Growth mixture modeling and related techniques for longitudinal data. In: Kaplan D, ed. The SAGE Handbook of Quantitative Methodology for the Social Sciences. Newbury Park, CA: Sage Publications; 2004:345-368.

26. Muthén LK, Muthén B. Mplus: Statisticsl Analysis With Latent Variables. User's guide. Los Angeles: Muthen \& Muthen; 2006.

27. Cardon G, Philippaerts R, Lefevre J, et al. Physical activity levels in 10- to 11-year-olds: clustering of psychosocial correlates. Public Health Nutr. 2005;8(7):896-903.

28. von Eye A, Bogat GA. Person orientation - concepts, results, and. development. Merrill-Palmer Q. 2006;52(3):390-420.

29. Feldman DE, Barnett T, Shrier I, Rossignol M, Abenhaim L. Is physical activity differentially associated with different types of sedentary pursuits? Arch Pediatr Adolesc Med. 2003;157(8):797-802.

30. Owen N, Leslie E, Salmon J, Fotheringham MJ. Environmental determinants of physical activity and sedentary behavior. Exerc Sport Sci Rev. 2000;28(4):153-158.
31. Prochaska JJ, Sallis JF, Sarkin JA, Calfas KJ. Examination of the factor structure of physical activity behaviors. J Clin Epidemiol. 2000;53(8):866-874.

32. Telama R, Yang X, Viikari J, Valimaki I, Wanne O, Raitakari O. Physical activity from childhood to adulthood: a 21-year tracking study. Am J Prev Med. 2005;28(3):267-273.

33. Myers L, Strikmiller PK, Webber LS, Berenson GS. Physical and sedentary activity in school children grades 5-8: the Bogalusa Heart Study. Med Sci Sports Exerc. 1996;28(7):852-859.

34. Raitakari OT, Porkka KV, Taimela S, Telama R, Rasanen L, Viikari JS. Effects of persistent physical activity and inactivity on coronary risk factors in children and young adults. The Cardiovascular Risk in Young Finns Study. Am J Epidemiol. 1994;140(3):195-205.

35. Dietz WH. The role of lifestyle in health: the epidemiology and consequences of inactivity. Proc Nutr Soc. 1996;55(3):829-840. 